
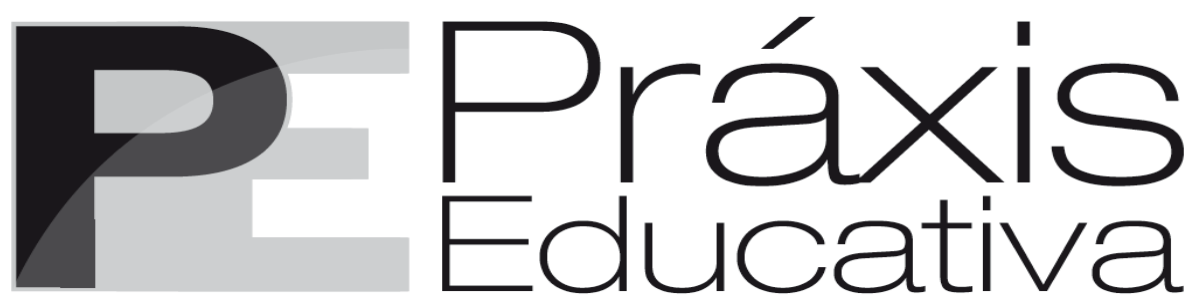

ISSN 1809-4031

eISSN 1809-4309

https://doi.org/10.5212/PraxEduc.v.16.17961.068

\title{
Supervisão Pedagógica: perspetivas de educadores de infância em Portugal ${ }^{*}$ \\ Pedagogical Supervision: perspectives of preschool teachers in Portugal
}

\section{Supervisión Pedagógica: perspectivas de educadores de infancia en Portugal}

Filipa Seabra*

https://orcid.org/0000-0003-1690-9502

Marta Abelha ${ }^{* * *}$

(iD https://orcid.org/0000-0001-7105-3722

Helena Miranda ${ }^{* * *}$

(iD https://orcid.org/0000-0002-8969-4947

Osvaldo Moreira ${ }^{* * * *}$

https://orcid.org/0000-0003-0420-9605

Resumo: Perante um contexto ainda pouco recetivo à supervisão pedagógica, mas assinalando mudanças e uma pressão crescente no sentido da sua valorização, o estudo realizado visou caracterizar as experiências e perspetivas de educadores de infância da rede pública em Portugal sobre a supervisão pedagógica. Foi aplicado um questionário previamente validado (GASPAR et al., 2019). Orientaram a pesquisa, perspetivas teóricas sobre supervisão pedagógica apresentadas por Gaspar (et al., 2019), Alarcão e Canha (2013), ou

\footnotetext{
* Esta pesquisa foi financiada por fundos nacionais através da FCT - Fundação Para a Ciência e a Tecnologia, I.P., pelos projetos UIDB/04372/2020 e UIDP/04372/2020.

** LE@D, Universidade Aberta, Portugal. Doutora em Ciências da Educação. Professora Auxiliar na Universidade Aberta (Portugal) e investigadora integrada do LE@D (Universidade Aberta, Portugal). É também investigadora colaboradora do CIEd (Universidade do Minho, Portugal) e do CIPEM/INET-MD (Portugal). E-mail: $<$ filipa.seabra@uab.pt>.

*** INPP, Universidade Portucalense, CEIS20, Universidade de Coimbra, LE@D, Universidade Aberta, Portugal. Doutora em Didática. Professora Auxiliar na Universidade Portucalense Infante D. Henrique e Professora Auxiliar Convidada da Universidade Aberta (Portugal). Investigadora integrada do CEIS20 (Universidade Coimbra, Portugal) e investigadora colaboradora do LE@D (Universidade Aberta, Portugal) e do INPP, Universidade Portucalense (Portugal).E-mail: <mabelha@upt.pt>.

****LE@D, Universidade Aberta, Portugal. Mestre em Supervisão Pedagógica. Investigadora do LE@D, Universidade Aberta, Portugal e Educadora de Infância. E-mail: <helenamir@gmail.com>.

***** LE@D, Universidade Aberta, Portugal. Mestre em Supervisão Pedagógica. Investigador do LE@D, Universidade Aberta, Portugal e Educador de Infância. E-mail: <osvaldo_moreira@silvessul.com>.
}

Práxis Educativa, Ponta Grossa, v. 16, e2117961, p. 1-21, 2021 Disponível em: < https:// revistas2.uepg.br/index.php/praxiseducativa> 
Roldão (2012), que têm sido fundamentais na definição do campo, em Portugal. Os resultados apontam para uma experiência de supervisão pedagógica muito ligada à avaliação do desempenho docente (ADD), e em menor medida à formação inicial de professores, considerada de reduzido impacto sobre a qualidade das práticas docentes. No entanto, as perspetivas sobre o papel do supervisor e o conceito de supervisão demonstram alguma abertura à possibilidade de uma supervisão mais horizontal e até informal produzir impactos positivos.

Palavras-chave: Supervisão pedagógica. Educação de Infância. Desenvolvimento profissional de professores.

\begin{abstract}
Faced with a context that is still not very receptive to pedagogical supervision, but experiencing change and growing pressure towards its valorization, the study carried out aimed at characterizing the experiences and perspectives of public-school preschool teachers in Portugal concerning pedagogical supervision. A previously validated questionnaire was applied (GASPAR et al., 2019). Theoretical perspectives on pedagogical supervision, such as those presented by Gaspar (et al., 2019), Alarcão and Canha (2013), or Roldão (2012), which have been fundamental in defining the field, in Portugal, were used. The results point to an experience of pedagogical supervision closely linked to teacher evaluation, and to a lesser extent to initial teacher training, considered to have little impact on the quality of teaching practices. However, perspectives on the role of the supervisor and the concept of supervision demonstrate some openness to the possibility of more horizontal and even informal supervision to produce positive impacts.

Keywords: Pedagogical supervision. Preschool teachers. Teacher professional development.
\end{abstract}

Resumen: Frente a un contexto todavía poco receptivo a la supervisión pedagógica, pero revelando cambios y crecientes presiones para su valorización, el estudio realizado tuvo como objetivo caracterizar las experiencias y perspectivas de educadores de infancia de escuelas públicas en Portugal sobre la supervisión pedagógica. Se aplicó un cuestionario previamente validado (GASPAR et al., 2019). Guiaron la investigación perspectivas teóricas sobre la supervisión pedagógica presentadas por Gaspar (et al., 2019), Alarcão y Canha (2013), o Roldão (2012). Los resultados apuntan a una experiencia de supervisión pedagógica estrechamente vinculada a la evaluación del desempeño docente, y en menor medida a la formación inicial de los docentes, considerada de escasa incidencia en la calidad de las prácticas docentes. Sin embargo, las perspectivas sobre el rol del supervisor y el concepto de supervisión demuestran cierta apertura a la posibilidad de una supervisión más horizontal e incluso informal para producir impactos positivos.

Palabras clave: Supervisión pedagógica. Educación infantil. Desarrollo profesional docente.

\title{
Introdução
}

O conceito de supervisão "integra dois étimos com raiz latina: "super" (com o significado de "sobre") e "vídeo" (com o significado de "ver"). De acordo com Gaspar, Seabra e Neves (2012), o primeiro significado de "super" resulta da "interpretação linear "olhar de ou por cima" (p. 30).

Seguindo o pensamento de Alarcão e Canha (2013) a supervisão define-se como "um processo de acompanhamento de uma atividade através de processos de regulação que são enquadrados por um referencial e operacionalizados por ações de monitorização em que a avaliação está obviamente presente" (p. 19). A supervisão pode oscilar entre duas modalidades - uma orientada sobretudo para a formação, o desenvolvimento e a aprendizagem, e outra focalizada no controlo, de pendor inspetivo e fiscalizador. Assim, estamos perante um conceito com duas tendências - por um lado uma orientação para a formação, centrada na possibilidade de desenvolvimento, e por outro, com uma forte carga de inspeção/fiscalização e centrada na verificação do cumprimento das normas.

Na mesma linha teórica, Gosling (2002, apud MCMAHON; BARRETT'; O'NEILL, 2007), identifica 3 modelos de observação da prática letiva - o modelo avaliativo, o modelo de desenvolvimento (que também inclui uma dimensão de avaliação sumativa) e o modelo de revisão por pares. Neste último

Práxis Educativa, Ponta Grossa, v. 16, e2117961, p. 1-21, 2021

Disponível em: <https://revistas2.uepg.br/index.php/praxiseducativa $>$ 
caso, a intenção é mais formativa, os papéis de observador e observado são intercambiáveis e procura-se um feedback construtivo entre pares.

McMahon, Barret e O’Neil (2007) vão mais longe, definindo o seu modelo não em função de quem observa, mas de quem controla o fluxo da informação. Nessa senda, defendem que um modelo de supervisão verdadeiramente horizontal, em que o supervisionado detém o controlo sobre a informação é aquele com maior potencial para suscitar abertura (em detrimento do desejo de encenar uma realidade apelativa e mais bem avaliada) e, assim, provocar mudanças. Nesta perspetiva, é o supervisionado quem decide o que é reportado e a quem. A supervisão entre pares terá, ainda, evidentes repercussões nas práticas reflexivas: "Esta é a diferença crucial que torna este modelo compatível com a ideia do professor reflexivo - porque é o único modelo no qual a reflexão não fica num inevitável segundo plano"1 (MCMAHON; BARRET; O'NEIL, 2007, p. 505).

Os autores (MCMAHON; BARRET; O'NEIL, 2007) assumem como princípios norteadores a voluntariedade de participação no processo de supervisão, a escolha do observador, a escolha do foco da observação, o controlo sobre a forma como o feedback será devolvido, o controlo sobre a informação resultante da observação e o controlo sobre as consequências da observação. Esta perspetiva, perfilhada em Portugal por experiências como a de Par em Par (MOURAZ; PEGO, 2016), é ainda pouco conhecida no terreno, sobrepondo-se frequentemente a associação entre supervisão e avaliação do desempenho docente (ADD) ${ }^{2}$, na qual, pelo contrário, o supervisionado tem consequências inalienáveis, em termos de progressão na carreira, da observação que é feita, não detendo o poder no sentido antes identificado. Assim, e embora se possa considerar que a ADD integra "uma estratégia global que visa proporcionar a melhoria e o sucesso sustentado das organizações" (MESQUITA-ALVES; COSTA; COSTA, 2013, p. 31), a sua confusão frequente com outras perspetivas e práticas de supervisão poderá contribuir para a tensão entre a dimensão avaliativa/fiscalizadora e a dimensão formativa/colaborativa da supervisão - cujo contributo para o desenvolvimento pessoal parece relevante: "agindo sobre as práticas docentes a supervisão pode assumir uma perspetiva transformadora contribuindo para o desenvolvimento profissional dos professores (OLIVEIRA; MIRANDA; BARREIRA, 2020, p. 20).

Já em 1993, Vieira defendia um conceito de supervisão orientado para a autonomia do supervisionado, assente na reflexividade e entendida com um "espaço de transformação pessoal e social" (p. 54). A autora (VIEIRA, 2009) tem vindo a defender uma supervisão de natureza transformadora, numa orientação emancipatória, com vista à melhoria das práticas educativas.

Mais recentemente, Moreira (2015) salienta que "O conceito de supervisão [...] se coloca ao serviço da qualidade em educação [...] enquanto teoria e prática de regulação crítica e colaborativa da pedagogia e do desenvolvimento profissional, numa visão da educação para a transformação e para a sustentabilidade” (p. 48).

Assumindo as raízes do conceito uma perspetiva fiscalizadora, constatamos que o mesmo tem experimentado, em Portugal, uma evolução assinalável no sentido de uma perspetiva menos hierarquizada (horizontal $v s$. vertical), mais colaborativa ( $v$ s. inspetiva), menos baseada em técnicas

\footnotetext{
${ }^{1}$ No original: "This is the crucial difference that makes this model compatible with the idea of the teacher as reflective practitioner - since it is the only model in which the reflection does not take an inevitable second place". (Tradução nossa).

2 Plasmada em sucessivos normativos desde 2008 (Decreto Regulamentar n. ${ }^{\circ}$ 2/2008, de 10 de Janeiro) e especialmente com o Decreto Regulamentar n. ${ }^{\circ}$ 2/2010 de 23 de junho (o qual refere a observação de aulas) e com o Decreto regulamentar n..$^{\circ}$ 26/2012, de 21 de fevereiro onde a terminologia supervisão surge relativamente ao avaliador externo, no artigo $13 .^{\circ}$, alínea c), que menciona a formação em supervisão como uma das condições para o exercício do cargo, além da continuidade da observação de aulas, inscrita no seu artigo 18..
}

Práxis Educativa, Ponta Grossa, v. 16, e2117961, p. 1-21, 2021 Disponível em: < https:// revistas2.uepg.br/index.php/praxiseducativa> 
e normas e mais orientada para a reflexão, o questionamento (reflexiva, entre pares e informal, vs. formal, burocrática) (SANCHES, 2019, p. 149; PEDRAS; SEABRA, 2016).

Tem emergido também com especial relevância uma perspetiva colaborativa e interpares associada à supervisão (ALARCÃO; CANHA, 2013; PEDRAS; SEABRA, 2016; MARCOS; MACHADO; ABELHA, 2015; AMARAL, 2019), defendendo que "os profissionais aprendem na interação com os seus colegas, tornando-se bem mais evidente, neste caso, a aliança entre supervisão e colaboração" (ALARCÃO; CANHA, 2013, p. 54). Esta orientação para a colaboração associada ao desenvolvimento profissional docente tem também sido reconhecida noutros contextos, incluindo o brasileiro (MEYER; VOSGERAU; BORGES, 2018).

Amaral (2019, p. 90) regista a relevância da supervisão colaborativa para a construção de escolas eficazes:

Permitem, numa perspetiva reguladora, acima de tudo, promover um trabalho colaborativo que conduzirá a uma cultura organizacional que culminará na melhoria da eficácia da Escolas.

A SP [supervisão pedagógica] atua como gestora das atividades da escola, especialmente no fortalecimento das articulações entre os diversos setores da instituição, nos aspetos pedagógicos, nas relações intersociais e principalmente nos relacionamentos em sala de aula no que diz respeito a aprendizagem e interação social dos alunos.

Através do processo de Avaliação Externa das Escolas (AEE), atualmente no seu terceiro ciclo de implementação, constata-se, também, uma pressão central no sentido de induzir práticas de supervisão. Embora a noção de supervisão esteja presente nos referenciais que orientam esse processo desde a sua génese, no terceiro ciclo de AEE (IGEC, 2018) é possível constatar uma orientação clara para a promoção de "mecanismos de regulação por pares e trabalho colaborativo" (p. 6), o que poderá influenciar a forma como a escola se posiciona face à supervisão pedagógica (MIRANDA; SEABRA, 2019). A análise dos relatórios deste ciclo de AEE permite identificar uma perspetiva bastante crítica, que reforça a ideia de incipiência das práticas de supervisão desenvolvidas nas escolas, a par da valorização de elementos ainda contraditórios da supervisão, que englobam uma perspetiva vertical, horizontal e até de autossupervisão (SEABRA, et al., no prelo).

\section{Locus da supervisão}

Para além da perspetiva mais tradicional da supervisão, que ocorre numa díade de supervisor - supervisionado, como por exemplo na perspetiva clínica (ALARCÃO; TAVARES, 2003), é também possível promover o desenvolvimento profissional através do trabalho entre um supervisor e um grupo de professores (SERGIOVANNI; STARRATT, 2002).

Outros cenários são equacionados: de acordo com Silva e Martins (2020, p. 145) a autossupervisão "implica a auto-observação, a análise e a reflexão sobre as próprias práticas, ou seja, entendemos que há autossupervisão quando a reflexão é efetuada pelo próprio sujeito com o intuito de melhorar o seu desempenho e, por inerência, o processo de ensino e aprendizagem".

No outro extremo deste continuum, podemos falar de supervisão escolar, orientada para a aprendizagem e o desenvolvimento da escola como organização, ideia que bebe do conceito de escola aprendente desenvolvida por Senge (1999 apud MAIO; SILVA; LOUREIRO, 2016) e que tem vindo a ser apoiada em Portugal por vários autores (ALARCÃO; ROLDÃO, 2010, VIEIRA, 1993). Neste seguimento, é possível defender que, "a supervisão não se restringe necessariamente

Práxis Educativa, Ponta Grossa, v. 16, e2117961, p. 1-21, 2021 
à regulação de processos de ensino e aprendizagem e pode alargar-se à escola como organização reflexiva” (MIRANDA; SEABRA, 2019, p. 144).

\section{Supervisão no contexto da educação de infância em Portugal}

Uma breve passagem pelo estado da arte em relação às publicações de âmbito nacional sobre supervisão pedagógica no contexto da educação de infância permitiu identificar uma produção ainda limitada e, sobretudo, circunscrita a trabalhos académicos, o que fundamenta a pertinência de publicar os resultados encontrados numa publicação de maior alcance.

São mais frequentes os trabalhos que situam a supervisão pedagógica no contexto da formação inicial de educadores. Note-se que em Portugal, o termo de supervisão surge associado à formação inicial de professores em 1988, com o Decreto-Lei n. ${ }^{\circ}$ 287/88, de 19 de agosto. Este versava a criação do Modelo de Profissionalização em Serviço, que tinha como finalidade profissionalizar docentes que não detinham habilitação profissional para a docência, dotando-os de competências pedagógicas específicas inerentes ao desenvolvimento do currículo.

De acordo com Alarcão e Tavares (2003, p. 4) "o termo supervisão começava a ser usado entre nós como alternativa à designação de "orientação da prática pedagógica", associada aos requisitos da formação inicial de professores e só mais tarde a esta "função de fiscalização e superintendência" se adicionou a vertente de "acompanhamento do processo formativo", colocando o enfoque no desenvolvimento profissional docente. Como lembra Marcelo (2009) e regulamenta o Perfil Geral de Desempenho Docente (Decreto-lei n. ${ }^{\circ}$ 240/2001), o professor tem de ser um profissional em aprendizagem contínua: "ser professor no século XXI pressupõe o assumir que o conhecimento e os alunos (as matérias-primas com que trabalham) se transformam a uma velocidade maior à que estávamos habituados e que, para se continuar a dar uma resposta adequada ao direito de aprender dos alunos, teremos de fazer um esforço redobrado para continuar a aprender" (MARCELO, 2009, p. 8). O autor explicita o percurso necessário para que os docentes sejam capazes de constituir-se como verdadeiros peritos adaptativos e não se quedem na sua presunção de peritos rotineiros: "o desenvolvimento profissional docente pode ser entendido como uma atitude permanente de indagação, de formulação de questões e procura de soluções" (MARCELO, 2009, p. 9). Neste contexto, torna-se imprescindível uma mudança de perspetiva e, consequentemente, de atitude, num entendimento e numa práxis construtivista:

\footnotetext{
De uma formação desenvolvida fora da escola para formas múltiplas de desenvolvimento profissional realizadas na escola;

De uma orientação baseada na transmissão aos docentes de conhecimentos e das competências feita por especialistas, ao estudo dos processos de ensino e de aprendizagem, pelos professores; De um desenvolvimento profissional dirigido aos professores, como principais destinatários, a um outro dirigido a todas as pessoas implicadas no processo de aprendizagem dos alunos; De um desenvolvimento profissional dirigido ao professor, a título individual, à criação de comunidades de aprendizagem, em que todos - professores, alunos, diretores, funcionários - se consideram, simultaneamente, professores e alunos. (MARCELO, 2009, p. 11).
}

Focando a atenção na supervisão vocacionada para o desenvolvimento profissional, mas, também na formação inicial, num percurso pelas investigações na área da supervisão em contexto de educadores de infância (que se revela, como referido, algo escasso), apresentam-se algumas investigações.

Relativamente à formação inicial, Correia, Matos e Figueira (2021) apresentam "o modelo de supervisão pedagógica em contexto de formação de educadores de infância” (p. 1) de um

Práxis Educativa, Ponta Grossa, v. 16, e2117961, p. 1-21, 2021

Disponível em: <https://revistas2.uepg.br/index.php/praxiseducativa $>$ 
mestrado de uma instituição portuguesa. Também Neves (2017) aborda na sua dissertação as implicações de um modelo reflexivo de supervisão aplicado à formação inicial de educadores de infância. Pereira (2017) identifica a presença de uma perceção positiva da prática supervisionada e da sua relevância na formação inicial por parte de educadores de infância.

Sanches (2019) salienta, com base em estudos realizados e na sua experiência enquanto formadora de educadores de infância, a importância que a supervisão tem nesse contexto, e ao mesmo tempo, as "tensões e contradições" (p. 148) que ainda envolvem esse processo, e que considera importante ultrapassar. Apesar de se centrar numa perspetiva formativa e colaborativa da supervisão dos educadores de infância, foca o seu trabalho no contexto da formação inicial.

No plano do desenvolvimento profissional, embora distante no tempo, será de mencionar o estudo de Paramos (2010), tendo como metodologia a investigação-ação, localizado num estabelecimento de educação de infância de Lisboa, porque assume um posicionamento formativo e colaborativo que mantém a sua atualidade. Trata-se de uma investigação desenvolvida na linha de uma supervisão clínica, colaborativa, com o objetivo de fomentar o trabalho entre educadoras de infância e "tentar compreender qual a influência destas ações no desenvolvimento profissional e na mudança do desempenho das práticas educativas dos educadores" (resumo, p. ii), recorrendo, entre outros procedimentos, a entrevistas de grupo focal para monitorizar o trabalho e recolher informações. Entre os resultados alcançados, salienta-se o trabalho colaborativo como frutuoso, ao nível da melhoria e da reflexão sobre a sua prática pedagógica; relações mais próximas e de partilha de ideias, valores e saberes. Contudo, foi reconhecido que esta exposição das práticas perante outros docentes pode ser constrangedora e que houve alguma dificuldade na aceitação de críticas à prática pedagógica por parte de outros. Percebeu-se, ainda, alguma resistência à palavra supervisão, sendo referido que seria antes, colaboração, mesmo tratando-se de observações de aulas interpares.

Também numa ótica de desenvolvimento profissional de educadores de carreira, Rosa (2021) analisa a supervisão pela perspetiva dos coordenadores de departamento pré-escolar, colocando-se assim na perspetiva de uma supervisão associada ao desempenho de uma função hierárquica. A este respeito "os coordenadores e as educadoras demonstram um conhecimento muito superficial e inconsistente da supervisão pedagógica, não ocorrendo processos supervisivos formais em nenhuma das duas instituições onde foi desenvolvido o estudo" (resumo, s.p.).

Fardilha (2020), num estudo de caso qualitativo em duas instituições escolares, identifica que "supervisão pedagógica e supervisão organizacional são vistas como fundamentais para a qualidade das instituições de Educação de Infância, embora as práticas supervisivas existentes sejam informais e sem intencionalidade" (resumo, s.p.).

Fazendo uma síntese dos resultados de diversos estudos realizados sobre supervisão - e perante a intenção de identificar as representações que a população docente tem sobre a supervisão pedagógica - encontram-se frequentemente opiniões que divergem entre a função de fiscalização, avaliação (COSTA, 2014; FERREIRA, 2013); a função de promover o desenvolvimento profissional e pessoal dos docentes e as aprendizagens dos alunos (FERREIRA, 2013; SANTOS; BRANDÃO, 2008; SOBRAL; CAETANO, 2016; PARAMOS, 2010); e a função de formação inicial de educadores de infância (SANTOS; BRANDÃO, 2008). Porém, vários autores convergem para a mesma conclusão, advogando, nos seus estudos, que a função da supervisão se baseia numa dimensão colaborativa (COSTA, 2014; FERREIRA, 2013; SALVADO, 2016; SOBRAL; CAETANO, 2016).

Numa perspetiva ainda original, Silva e Martins (2020) apresentam uma experiência de autossupervisão levada a cabo por uma educadora de infância, em colaboração com um amigo crítico.

Práxis Educativa, Ponta Grossa, v. 16, e2117961, p. 1-21, 2021

Disponível em: <https://revistas2.uepg.br/index.php/praxiseducativa $>$ 
Esta investigação revela o potencial transformador da prática desta experiência de autossupervisão e supervisão colaborativa.

Gaspar et al. (2019), realizando um estudo que abarcou diversos contextos de supervisão de professores, constatam, de forma transversal, que a supervisão foi entendida como necessária, com potencial transformador, ao mesmo tempo que verificaram a incipiência dos processos de supervisão em prática nesses vários contextos. Partindo dessa noção, e recorrendo a um dos instrumentos utilizados nesse estudo, aplicado agora ao contexto da educação de infância que não havia sido averiguado, formulámos a seguinte questão, como orientadora da investigação realizada: Quais as perspetivas de educadores de infância sobre supervisão pedagógica e o seu papel nas suas práticas pedagógicas? A partir desta questão, definimos como objetivos do estudo: Conhecer perspetivas de educadores de infância sobre o conceito de supervisão e caracterizar perspetivas de educadores de infância sobre as experiências de supervisão que tiveram ao longo da sua carreira e o seu impacto.

\section{Metodologia}

Foi aplicado um questionário desenvolvido por Gaspar et al. (2019) no contexto de um estudo sobre a supervisão na formação contínua de professores. Essa aplicação foi precedida da autorização dos autores do instrumento, e de uma ligeira reformulação de alguns itens, no sentido de os adequar à população que pretendíamos estudar.

A definição da pesquisa obedeceu a preocupações éticas, na medida em que procura responder a uma questão relevante para as práticas educativas que têm lugar nas escolas, podendo trazer benefícios para os participantes (CRESWELL, 2007). Atendendo às normas éticas da investigação em ciências da educação, foram garantidos o anonimato e a participação voluntária aos participantes (AERA, 2011; SPCE, 2020) assim contribuindo para a inexistência de riscos para os participantes. Numa fase posterior do estudo, a redação obedece a cuidados com o rigor na análise dos dados e o cumprimento escrupuloso dos deveres assumidos para com os participantes em termos do anonimato e proteção dos dados (CRESWELL, 2007), e por fim, os cuidados éticos refletem-se na determinação da autoria, que foi aferida mediante os procedimentos recomendados pela American Psychological Association (2015) ${ }^{3}$.

A recolha dos dados decorreu de forma mista - online e em suporte papel - durante o ano 2020. Os dados foram tratados de forma agregada, recorrendo ao software SPSS, incluindo análise de frequências, descritiva e correlacional.

Os participantes no estudo foram 65 educadores de infância de carreira, da rede pública portuguesa. Destes, 56 lecionavam em escolas da região sul do país, e 9 no norte de Portugal $^{4}$, em 2020.

Participaram no estudo 63 educadoras do sexo feminino $(96,9 \%)$ e 2 educadores do sexo masculino (3,1\%). As idades dos participantes variavam entre os 38 e os 63 anos (média $=51,38$, desvio padrão $=7,24)$, e o seu número de anos de serviço como educadores de infância variava entre 2 e 39 anos (média $=26,54$, desvio padrão $=9,09$ ).

\footnotetext{
${ }^{3}$ https://www.apa.org/science/leadership/students/authorship-determination-scorecard.pdf

${ }^{4}$ Os dados foram recolhidos no contexto de duas dissertações de mestrado, por dois dos autores do presente artigo, concretamente, Miranda (2021) e Moreira (2021).
}

Práxis Educativa, Ponta Grossa, v. 16, e2117961, p. 1-21, 2021 
Quanto ao grau académico mais elevado, a maioria detinha uma licenciatura ( $\mathrm{n}=45,70,3 \%$ válidos), embora se registassem ainda 7 respondentes com um bacharelato ( $\mathrm{n}=7,10,9 \%$ válidos), 8 com pós-graduação ou especialização (12,5\% válidos) e 4 com mestrado (6,3\% válidos) ${ }^{5}$. A maioria desempenhava funções de educador titular, sem outros cargos ( $\mathrm{n}=56,86,2 \%$ válidos).

\section{Apresentação e discussão dos resultados}

A maioria dos participantes não detinha formação complementar sobre supervisão pedagógica ou $\operatorname{ADD}(n=57,87,7 \%)$. Aqueles que tinham essa formação ( $n=8,12,3 \%)$, tinham sobretudo realizado cursos de curta duração, embora dois participantes indicassem ter especialização ou pós-graduação na área da supervisão pedagógica. Este resultado espelha a ideia defendida por Sanches (2019) de que continua a existir um fraco investimento na formação docente no domínio da supervisão pedagógica e que vai, ainda, contra o preconizado por Alarcão que defende que "o desempenho da função da supervisão, pela sua natureza, pressupõe pré-requisitos e formação especializada" (2020, p. 31).

Novamente, a maioria não detinha experiência enquanto supervisor ou avaliador do desempenho docente $(n=54,83,1 \%)$. A experiência mais frequente era no âmbito da ADD ( $n=9$, 13,8\%), com apenas 1 educador a relatar ter experiência como supervisor, não relacionada com a $\mathrm{ADD}$, e 1 educador a indicar ter experiência como supervisor, quer ligada à $\mathrm{ADD}$, quer dissociada dela. A situação inverte-se quando analisamos a experiência dos participantes como alvos de supervisão: a maioria foi, alguma vez, supervisionada ( $\mathrm{n}=53,81,5 \%)$.

\section{Experiências prévias de supervisão}

Entre aqueles que foram alvo de supervisão, essa experiência consistiu, sobretudo, na observação da prática letiva em sala de aula $(\mathrm{n}=39,76,3 \%)$, reflexão sobre as práticas desenvolvidas $(\mathrm{n}=32,60,4 \%)$ e aplicação de grelhas de planificação ou avaliação $(\mathrm{n}=27,50,9 \%)$. Estes resultados contrastam com os encontrados por Gaspar et al. (2019), nos quais a observação da prática letiva em sala de aula surgia apenas em sétimo lugar, assumindo o primeiro lugar a aplicação de grelhas de planificação/avaliação, o segundo a aferição de critérios de avaliação, e o terceiro a reflexão sobre as práticas. Os participantes do nosso estudo parecem, assim, ter tido uma experiência diferente de supervisão, eventualmente menos burocrática do que a dos participantes do estudo a que nos referimos, no contexto dos Centros de Formação dos Agrupamentos de Escolas (CFAE), indo assim ao encontro da ideia defendida por Alarcão e Roldão (2010) de que a supervisão impele a uma reflexão sobre o que cada um faz, porquê e como o faz, podendo contribuir para o crescimento pessoal e profissional dos educadores.

\footnotetext{
${ }^{5}$ Em Portugal, atualmente, o acesso à docência exige o grau de mestre. No entanto, tratando-se de profissionais muito experientes, na sua maioria, isso justifica que ainda exista uma maioria que detém graus inferiores ao mestrado. $\mathrm{O}$ Bacharelato pressupunha uma formação superior de 3 anos, e a licenciatura pré-Bolonha, 4 ou 5 anos de estudos superiores.
}

Práxis Educativa, Ponta Grossa, v. 16, e2117961, p. 1-21, 2021 
Gráfico 1 - Opções de resposta dos inquiridos à questão “Em que consistiu a supervisão?” de que foram alvo

\section{Em que consistiu a supervisão?}

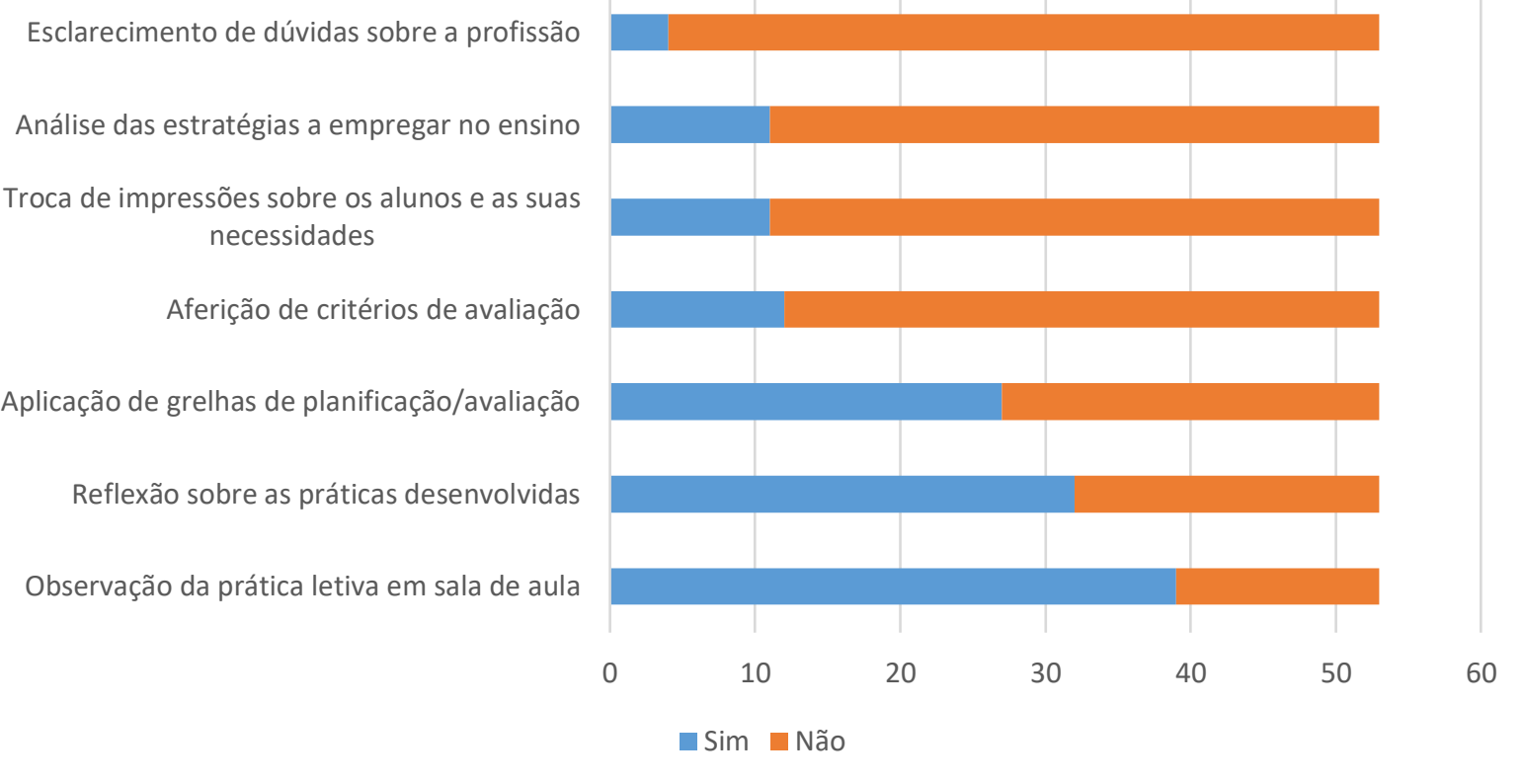

Fonte: Dos autores.

A figura do supervisor mais frequentemente apontada pelos participantes foi o Avaliador do Desempenho Docente ( $\mathrm{n}=36,56,3 \%$ ), seguido do Coordenador de educadores de infância $(\mathrm{n}=35,54,7 \%)$, e de figuras associadas à formação inicial de professores, seja o supervisor de estágio (professor universitário; $\mathrm{n}=20,31,3 \%$ ) ou o orientador de estágio (educador da escola onde decorreu o estágio; $n=17,26,6 \%$ ).

Gráfico 2 - Opções de resposta dos inquiridos quanto à figura do supervisor

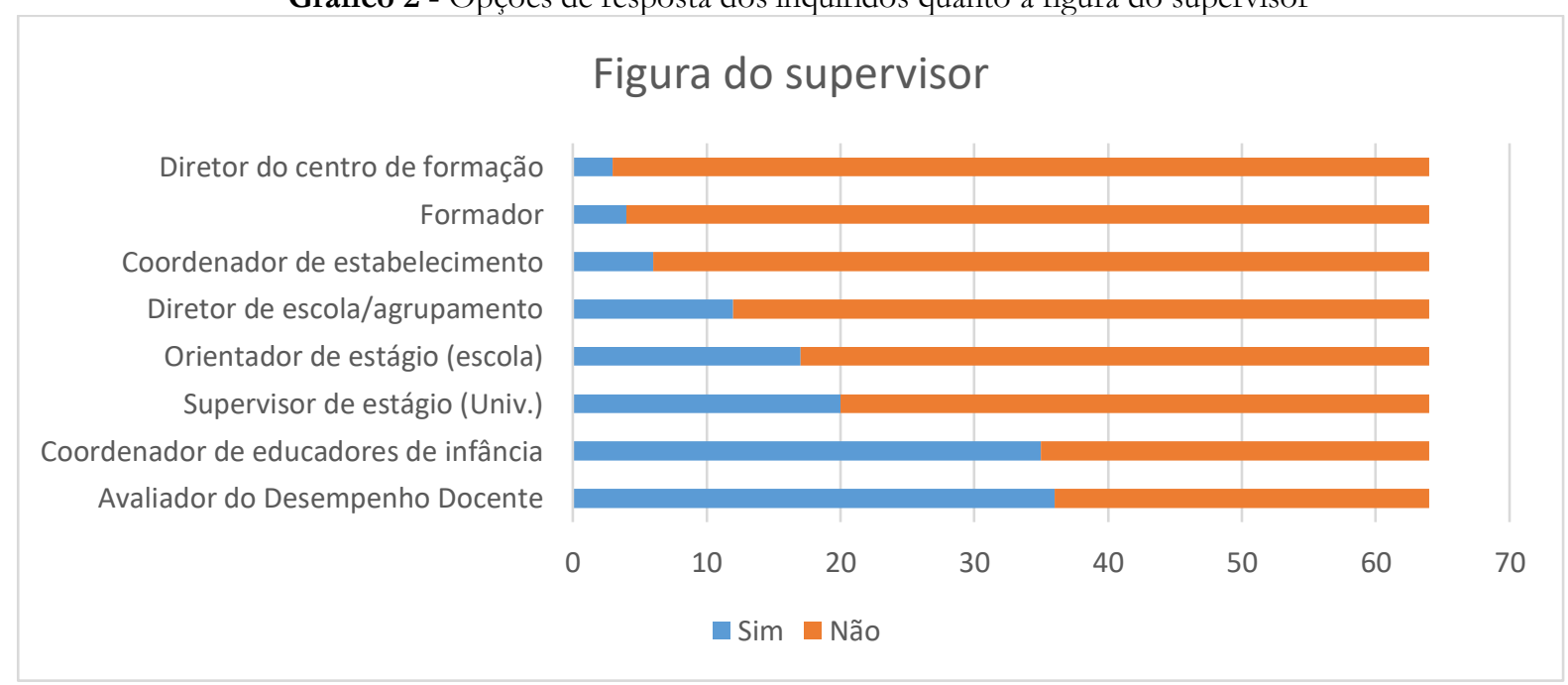

Fonte: Dos autores.

Práxis Educativa, Ponta Grossa, v. 16, e2117961, p. 1-21, 2021

Disponível em: < https://revistas2.uepg.br/index.php/praxiseducativa $>$ 
É de salientar que, embora em minoria, 9 participantes apontaram outras figuras de supervisor, indicando, num caso, uma Inspetora da Educação, e em 4 casos havendo alguma referência a processos de supervisão colaborativa, entre colegas. A título de exemplo, apresenta-se uma citação de uma resposta nesse sentido: "No âmbito do trabalho cooperativo, os colegas podem e devem desempenhar o papel de supervisor, planificando, assistindo às aulas de outros colegas, reunindo entre si para avaliar as estratégias usadas, o ambiente educativo em que as atividades decorrem e outros aspetos que possam ser relevantes". É relevante realçar que esta resposta foi dada por uma participante com formação complementar na área da supervisão pedagógica. Assim, salvaguardando algumas exceções, as experiências de supervisão que os participantes relataram e valorizaram, na sua memória, foram sobretudo as que se associam à ADD, e em menor escala, à formação inicial de professores, havendo assim um forte pendor avaliativo e vertical desses processos. Estes resultados vão ao encontro dos estudos desenvolvidos por Alarcão e Tavares (2003), Gaspar, Seabra e Neves (2012), Alarcão e Canha (2013), Gaspar et al. (2019) e Baptista (2019) que destacam a colagem/associação/confusão feita pelos Educadores e Professores, entre a supervisão pedagógica e a ADD, por exemplo. A este propósito, Alarcão (2000, p.18) reforça que a supervisão inicialmente só pensada em termos da formação inicial e do contexto de sala de aula necessita ser repensada numa dimensão mais ampla e como melhoria das práticas docentes e da escola como um todo.

Os participantes foram ainda questionados sobre os impactos que a supervisão de que foram alvo teve nas suas práticas. Os respondentes, embora assumindo uma diversidade de posições, situaram-se sobretudo no polo negativo, com $41,5 \%$ dos respondentes a considerar que a supervisão teve pouco ou nenhum impacto nas suas práticas, facto que vai ao encontro de resultados de estudos desenvolvidos por Vieira et al. (2010) e apenas 18,5\% a considerar que essa supervisão teve um impacto bastante importante ou muito importante.

Gráfico 3 - Opções de resposta dos inquiridos à questão sobre o impacto da supervisão de que foram alvo nas suas práticas pedagógicas

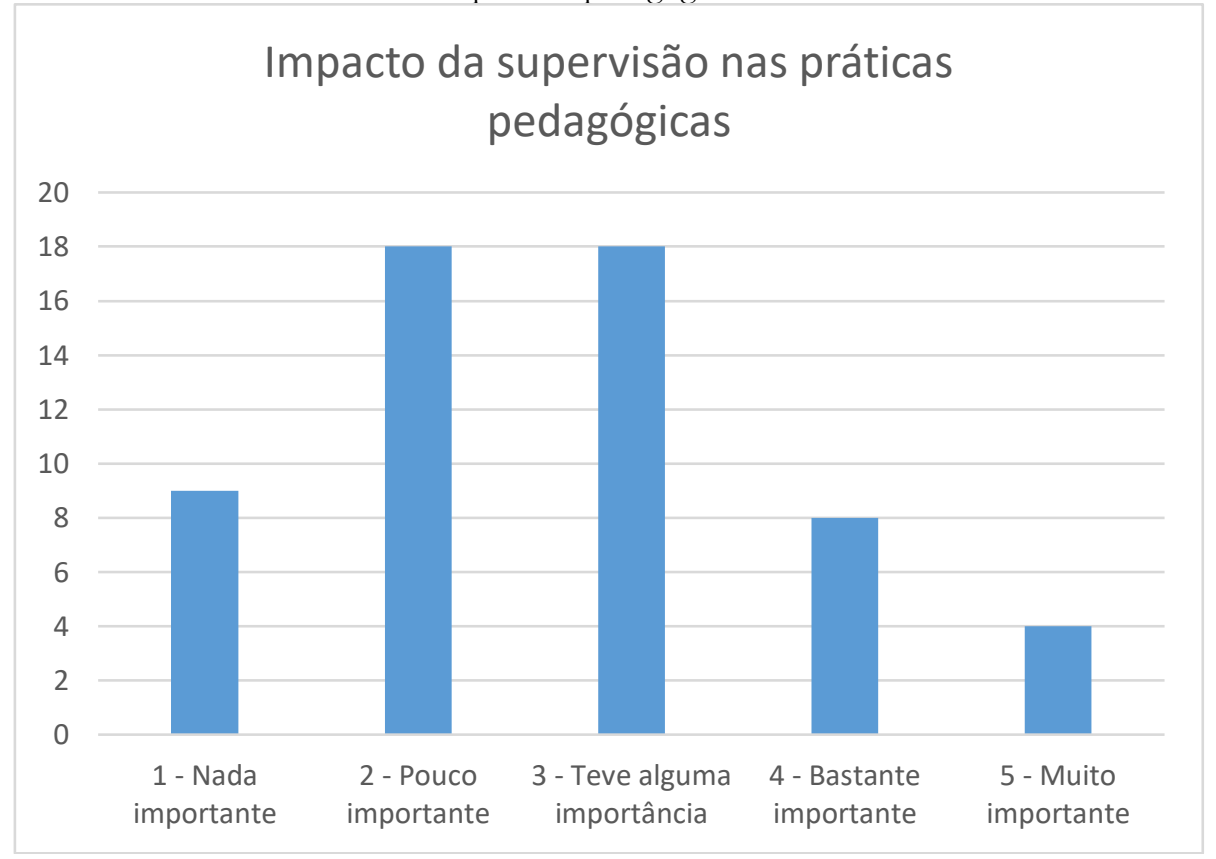

Fonte: Dos autores.

Práxis Educativa, Ponta Grossa, v. 16, e2117961, p. 1-21, 2021 Disponível em: <https://revistas2.uepg.br/index.php/praxiseducativa $>$ 


\section{Funções do supervisor}

Quando questionados sobre o papel do supervisor, os educadores foram convidados a escolher apenas 3 de entre 15 funções possíveis, e, dentro destas, a identificar a função mais prioritária (à qual fizemos corresponder 3 pontos), a segunda mais prioritária (à qual atribuímos 2 pontos) e a $3 .^{a}$ mais prioritária (à qual foi atribuído 1 ponto). Da soma das classificações efetuadas por 64 educadores, foi possível identificar as funções às quais foi atribuída maior e menor prioridade. É interessante constatar, que ao contrário da experiência relatada, muito associada a uma supervisão vertical e avaliativa, as funções que os educadores mais valorizam no papel do supervisor vão no sentido de uma supervisão reflexiva e orientada para a melhoria das práticas docentes: 'promover a reflexão' destaca-se claramente, com um total de 137 pontos atribuídos, seguindo-se 'orientar' (54 pontos), e 'analisar práticas' (44 pontos). Ideias associadas à avaliação (21 pontos), regulação (20 pontos), ou inspeção (6 pontos), surgem bem abaixo na lista das prioridades dos educadores, sinalizando que há uma discrepância importante entre a supervisão de que consideram ter sido alvos, e aquela que consideram prioritária. O apoio e a orientação, também consideradas funções importantes do supervisor do nosso estudo, foram também identificadas como fundamentais nos estudos de Baptista (2011), Ferreira (2013) e Fardilha (2020).

Gráfico 4 - Opções de resposta dos inquiridos à questão relativa às funções do supervisor

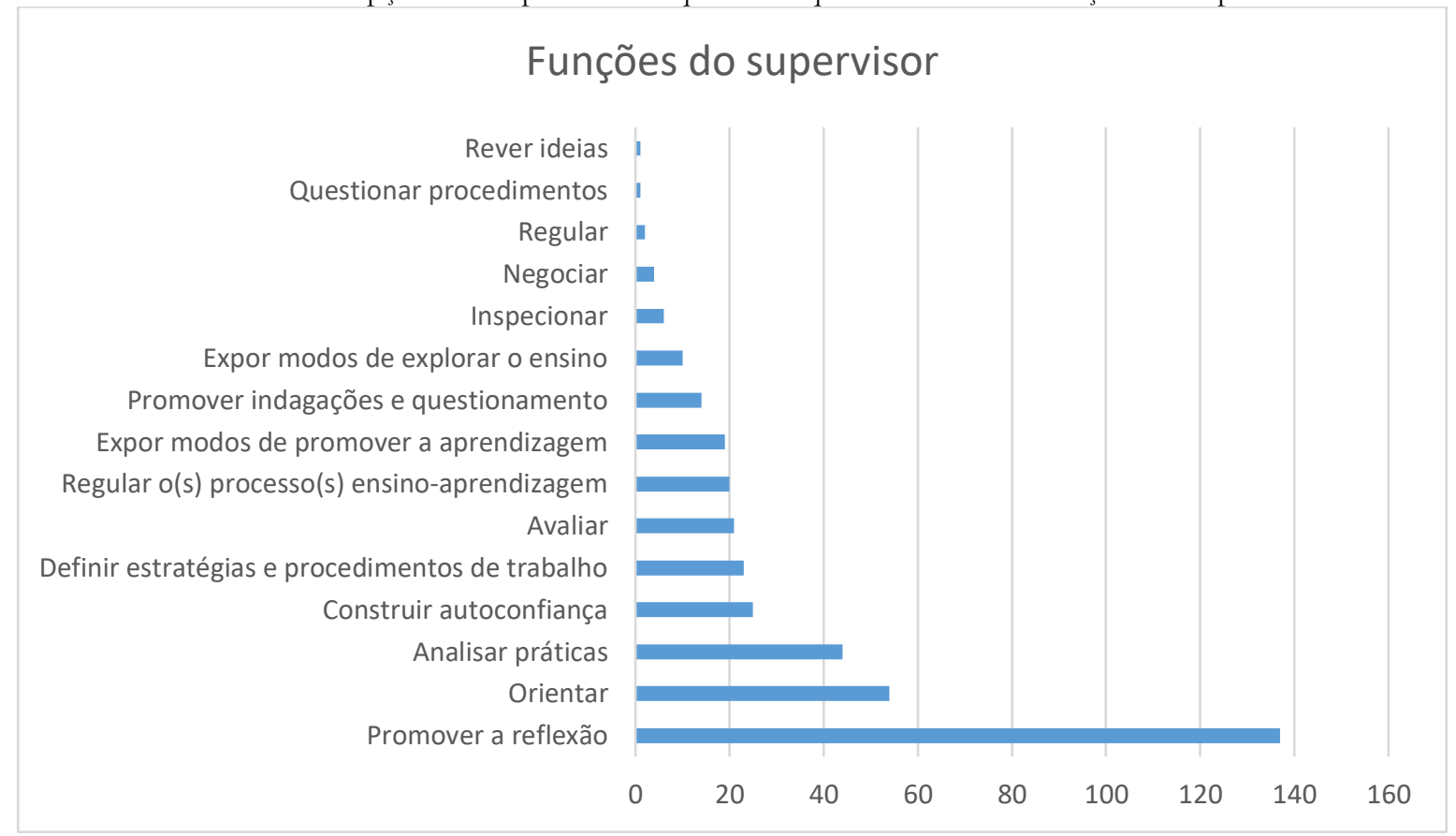

Fonte: Dos autores.

A análise correlacional revela que os docentes mais velhos tendem a dar maior peso às funções 'inspecionar' $(r=.299, \mathrm{p}<0.05)$ e 'orientar' $(\mathrm{r}=.290, \mathrm{p}<0.05)$. Por outro lado, o grau académico correlaciona-se negativamente com a função 'expor modos de promover a aprendizagem' ( $\mathrm{r}=-.290, \mathrm{p}<0.05)$, e o desempenho de cargos de gestão correlaciona-se com a valorização da função 'definir estratégias e procedimentos de trabalho $(r=.284, \mathrm{p}<0.05)$. Por fim, os docentes com formação específica em supervisão ou ADD parecem valorizar mais a função 'questionar procedimentos' ( $\mathrm{r}=.333, \mathrm{p}<0.01)$. 


\section{Conceito(s) de supervisão}

Relativamente aos conceitos de supervisão perfilhados pelos educadores entrevistados, eles podem ser analisados em relação a vários vetores, que, em alguns casos, podem constituir eles mesmos variáveis: impactos da supervisão, locus da supervisão, formalidade/verticalidade da supervisão, dimensões da supervisão e contexto da formação em que ocorre a supervisão.

Os impactos da supervisão aferidos, numa escala Likert de 1 (Discordo totalmente) a 5 (Concordo totalmente), dizem respeito aos impactos reconhecidos em 5 variáveis: melhoria da qualidade do trabalho dos professores, melhoria das relações profissionais entre professores, contributo para a formação contínua de professores, contributo para a melhoria da organização escolar e contributo para o desenvolvimento profissional docente. A análise de consistência de escala identificou um alfa de Cronbach de .883 , o que possibilita a soma destas variáveis e a análise global da escala resultante: impacto da supervisão pedagógica, cujo valor varia entre 5 e 25 . A média desta variável situa-se nos 14,98, com desvio padrão de 5,59, o que indica uma apreciação ligeiramente positiva dos impactos que a supervisão pode ter.

Esta escala correlaciona-se significativamente com a formação relacionada com a supervisão pedagógica ou a $\mathrm{ADD}(\mathrm{r}=.254, \mathrm{p}<0.05)$, o que indica uma tendência para os educadores com maior formação relacionada com estas áreas para valorizar os impactos da supervisão pedagógica.

Olhando individualmente para cada item, aquele que reúne maior concordância da parte dos educadores diz respeito ao contributo para a melhoria do trabalho docente (média $=3,29$, $\mathrm{DP}=1,35$ ) e para o desenvolvimento profissional docente (média $=3,22, \mathrm{DP}=1,41$ ). Pelo contrário, os docentes discordam que a supervisão contribua para a melhoria da organização escolar (média $=2,72, \mathrm{DP}=1,29$ ) ou para a melhoria das relações profissionais entre docentes (média $=2.77$, $\mathrm{DP}=1,36$ ) registando o restante item uma classificação média entre os 2,8 e os 3,2 pontos, que consideramos corresponder à zona de indefinição avaliativa dos respondentes.

Também Salvado (2016) conclui que "as Educadoras de Infância consideram o papel da Supervisão fundamental para a qualidade pedagógica da Educação Pré-escolar, mencionando a necessidade de se refletir cada vez mais sobre a prática, de a reformularmos, preconizando um modelo de escola enquanto comunidade reflexiva e aprendente" (p.104), defendendo assim que as participantes do estudo reconhecem potencial de impacto à supervisão, sempre que esta esteja assente numa reflexão sobre a prática.

Práxis Educativa, Ponta Grossa, v. 16, e2117961, p. 1-21, 2021 
Tabela 1 - Síntese de valores obtidos a partir das opiniões dos inquiridos face ao conceito de supervisão, no tocante ao seu impacto

Conceito de supervisão: Impacto da Supervisão Pedagógica

\begin{tabular}{|c|c|c|c|c|c|}
\hline & $\mathrm{N}$ & Mínimo & Máximo & Média & $\begin{array}{l}\text { Desvio } \\
\text { Padrão }\end{array}$ \\
\hline $\begin{array}{l}\text { Contribui para o desenvolvimento profissional } \\
\text { docente }\end{array}$ & 65 & 1 & 5 & 3,22 & 1,409 \\
\hline Contribui para a melhoria da organização escolar & 65 & 1 & 5 & 2,72 & 1,293 \\
\hline $\begin{array}{l}\text { Contribui para a formação contínua de } \\
\text { professores }\end{array}$ & 65 & 1 & 5 & 2,98 & 1,375 \\
\hline $\begin{array}{l}\text { Contribui para a melhoria da qualidade do } \\
\text { trabalho dos professores }\end{array}$ & 65 & 1 & 5 & 3,29 & 1,355 \\
\hline $\begin{array}{l}\text { Contribui para a melhoria das relações } \\
\text { profissionais entre professores }\end{array}$ & 65 & 1 & 5 & 2,77 & 1,355 \\
\hline
\end{tabular}

Fonte: Dos autores.

A análise correlacional revela que os respondentes mais velhos $(\mathrm{r}=-.274, \mathrm{p}<0.05)$, e também aqueles que detém maior experiência $(\mathrm{r}=-.261, \mathrm{p}<0.05)$, tendem a discordar mais da ideia de que a supervisão contribui para a melhoria das relações entre professores, ao contrário do que havia sido registado por Gaspar e colaboradores (2019), numa amostra de formadores. Por outro lado, a formação especializada na área da supervisão ou ADD correlaciona-se com a ideia de que a supervisão contribui para a melhoria da qualidade de trabalho dos professores $(r=.343, p<0.01)$, e para a melhoria da organização escolar $(r=.258, \mathrm{p}<0.05)$.

Relativamente ao locus da supervisão, incluem-se nesta dimensão do questionário 4 itens que medem a posição dos respondentes quanto à possibilidade de a supervisão decorrer de forma individual, diádica, grupal, e abrangendo a escola como um todo.

As características de consistência entre estes itens não recomendam a sua análise agregada, pelo que os analisaremos individualmente. Entre estes modelos de supervisão, apenas aquele que remete para uma relação diádica recebeu o acordo dos respondentes (média=3,69, DP=1,02). As restantes possibilidades foram apreciadas com valores médios entre os 2,91 e os 3,06, o que indica uma posição indefinida dos educadores. Iniciativas como a de Silva e Martins (2020) que promovem a autossupervisão de educadores de infância, não são ainda reconhecidas pelos participantes do estudo como uma possibilidade válida de supervisão orientada para o desenvolvimento profissional.

Tabela 2 - Síntese de valores obtidos a partir das opiniões dos inquiridos em relação ao conceito de supervisão, no tocante ao seu locus

\section{Conceito de supervisão: Locus da supervisão}

\begin{tabular}{l|c|c|c|c|c}
\hline & $\mathrm{N}$ & Mínimo & Máximo & Média & Desvio Padrão \\
\hline $\begin{array}{l}\text { Pode acontecer numa relação diádica entre supervisor } \\
\text { e supervisionado }\end{array}$ & 64 & 1 & 5 & 3,69 & 1,022 \\
\hline Pode acontecer de forma grupal & 65 & 1 & 5 & 3,06 & 1,210 \\
\hline Pode abranger a escola como um todo & 65 & 1 & 5 & 3,02 & 1,256 \\
\hline Pode acontecer, isoladamente, por reflexão individual & 64 & 1 & 5 & 2,91 & 1,178 \\
\hline
\end{tabular}

Fonte: Dos autores.

Práxis Educativa, Ponta Grossa, v. 16, e2117961, p. 1-21, 2021 
A formação especializada em supervisão pedagógica, ou ADD correlaciona-se com a perspetiva de que a supervisão pode ocorrer numa díade supervisor/supervisionado $(r=.269$, $\mathrm{p}<0.05)$. O estudo de Gaspar e colaboradores (2019) tinha encontrado uma correlação negativa entre a idade e a perspetiva de a supervisão abranger toda a escola, o que não se verificou no nosso estudo.

$\mathrm{Na}$ dimensão formalidade-verticalidade $v$ s. informalidade-horizontalidade, incluíram-se 6 itens, que, por implicarem respostas de sentido contrário, são analisados individualmente: a supervisão requer a aplicação de um modelo previamente definido; implica uma relação formal, segundo critérios pré-definidos; requer uma relação assimétrica entre supervisor e supervisionado; requer que o supervisor tenha maior experiência e/ou formação que o supervisionado e, no sentido inverso, pode acontecer de modo informal; e pode acontecer entre colegas/pares.

As respostas a estes itens indicam que os educadores consideram que a supervisão pode ocorrer de modo informal (média $=3,63, \mathrm{DP}=1,19$ ), pode ocorrer entre pares (média $=3,54$, $\mathrm{DP}=1,31$ ), embora considerem também que requer que o supervisor tenha maior experiência ou conhecimento que o supervisionado (média=3,45, DP=1,39), sendo que este último aspeto vai no sentido da perspetiva de Alarcão e Tavares que defendem a supervisão pedagógica como a posição de orientação de um profissional mais qualificado a um outro, no intuito de melhorar o seu trabalho docente: "o supervisor surge, deste modo, como alguém que tem por missão ensinar, ou melhor, facilitar a aprendizagem do professor" (2003, p. 42).

Por outro lado, discordam da necessidade de assimetria na relação entre supervisor e supervisionado (confirmando, assim, o acordo com uma perspetiva de supervisão entre pares) (média $=2,45, \mathrm{DP}=1,08$ ) e também da necessidade de uma relação formal (confirmando o acordo com uma supervisão informal) (média $=2,72, \mathrm{DP}=1,15)$. Não apresentam uma opinião definida sobre a necessidade de a supervisão seguir um modelo pré-definido (média $=3,05, \mathrm{DP}=1,41$ ).

Outros estudos com educadores de infância haviam já identificado a preferência desta população por uma supervisão de matriz colaborativa, nomeadamente:

Ferreira (2013): "Para estes docentes a Supervisão Pedagógica só faz sentido se for realizada numa perspetiva de apoio, de ajuda, de promoção do trabalho colaborativo, ou seja, num processo contínuo de acompanhamento e monitorização" (p. 52);

Salvado (2016): "Podemos concluir que as Educadoras de Infância encaram a Supervisão Pedagógica de uma forma positiva se esta adotar uma dimensão colaborativa, assim como acreditam que esta poderá contribuir para a mudança de mentalidades e para a inovação nas escolas" (p. 104). 
Tabela 3 - Síntese de valores obtidos a partir das opiniões dos inquiridos face ao conceito de supervisão, no tocante ao seu grau de formalidade e/ou verticalidade

\begin{tabular}{l|c|c|c|c|c}
\hline \multicolumn{5}{c}{ Conceito de supervisão: Formalidade/verticalidade } \\
\hline $\begin{array}{l}\text { Requer a aplicação de um modelo previamente } \\
\text { definido }\end{array}$ & $\mathbf{N}$ & Mínimo & Máximo & Média & Desvio Padrão \\
\hline $\begin{array}{l}\text { Implica uma relação formal, segundo critérios pré- } \\
\text { estabelecidos }\end{array}$ & 65 & 1 & 5 & 3,05 & 1,408 \\
\hline Pode acontecer de modo informal* & $\mathbf{6 5}$ & $\mathbf{1}$ & $\mathbf{5}$ & $\mathbf{3}, \mathbf{6 3}$ & $\mathbf{1 , 1 2}$ \\
\hline Pode acontecer entre colegas/pares* & $\mathbf{6 5}$ & $\mathbf{1}$ & $\mathbf{5}$ & $\mathbf{3 , 5 4}$ & $\mathbf{1 , 3 1 2}$ \\
\hline $\begin{array}{l}\text { Requer que o supervisor tenha maior experiência e/ou } \\
\text { formação que o supervisionado }\end{array}$ & 65 & 1 & 5 & 3,45 & 1,392 \\
\hline $\begin{array}{l}\text { Requer uma relação assimétrica entre supervisor e } \\
\text { supervisionado }\end{array}$ & 65 & 1 & 5 & 2,45 & 1,076 \\
\hline
\end{tabular}

Fonte: Dos autores.

* Os itens identificados com asterisco indicam uma perspetiva inversa aos restantes: o acordo com estes itens implica menor formalidade/verticalidade.

Curiosamente, o desempenho de cargos de gestão correlaciona-se com a noção de que a supervisão pode ocorrer entre pares $(\mathrm{r}=.246, \mathrm{p}<0.05)$.

No estudo de Gaspar e colaboradores (2019), tinham sido encontradas correlações entre a idade e uma perspetiva mais vertical/formal da supervisão, nomeadamente quanto ao requisito de que o supervisor tivesse maior experiência ou formação, e à rejeição da ideia de que a supervisão pode ocorrer de modo informal. Esta situação não se repetiu na amostra que estudámos, podendo sinalizar diferenças entre os grupos, ou uma mudança de atitude por parte dos respondentes quanto à supervisão. Entre os formadores, tinha-se constatado uma associação da supervisão "sobretudo a processos avaliativos" (GASPAR, et al., 2019, p. 111).

No tema das dimensões que o termo de supervisão integra, incluem-se 6 itens, 'requer um processo de avaliação', 'implica a relação entre as componentes formal e não-formal do currículo', 'requer um processo de acompanhamento', 'requer um processo de orientação', 'requer um processo de liderança' e 'requer a observação da prática letiva em sala de aula'.

Neste âmbito, reúnem apreciações positivas a associação do conceito de supervisão a processos de orientação (média $=3,49, \mathrm{DP}=1,19)$ e a processos de acompanhamento (média =3,34, $\mathrm{DP}=1,34)$. Pelo contrário, apreciam negativamente a necessidade de associação entre supervisão e liderança (média=2,64, DP=1,34). As restantes dimensões encontram-se numa margem de indefinição, com valores muito próximos do 3.

Os resultados identificados diferem dos de Costa (2014) e Ferreira (2013) que apontavam no sentido de uma conceção de supervisão mais associada à inspeção e avaliação, aproximando-se de outros resultados (por vezes encontrados pelos mesmos autores, o que realça a dicotomia de perspetivas sobre supervisão que ainda persiste) que ressalvam uma supervisão de natureza mais colaborativa e formativa (COSTA, 2014; FERREIRA, 2013; SALVADO, 2016; SOBRAL; CAETANO, 2016). Podemos assim estar a afastar-nos do cenário constatado em 2014, quando Costa considera:

Parece-nos que, apesar das conceções e práticas de supervisão não obedecerem como desejaríamos, a uma intencionalidade e se encontrem, ainda, "presas" a conceitos menos atualizados e ainda próximos das conceções de supervisão enquanto avaliação e fiscalização próprios de realidades onde se pretende aumentar o rendimento e a produção, podemos, efetivamente, falar de supervisão na educação de infância nas IPSS (2014, p. 84).

Práxis Educativa, Ponta Grossa, v. 16, e2117961, p. 1-21, 2021 Disponível em: < https://revistas2.uepg.br/index.php/praxiseducativa $>$ 
Tabela 4 - Síntese de valores obtidos a partir das opiniões dos inquiridos face ao conceito de supervisão, em relação às suas dimensões

\begin{tabular}{l|c|c|c|c|c}
\hline \multicolumn{5}{c}{ Conceito de supervisão: Dimensões da supervisão } \\
\hline & $\mathrm{N}$ & Mínimo & Máximo & Média & Desvio Padrão \\
\hline $\begin{array}{l}\text { Requer a observação da prática letiva em sala de } \\
\text { aula }\end{array}$ & 65 & 1 & 5 & 3,09 & 1,343 \\
\hline Requer um processo de liderança & 64 & 1 & 5 & 2,64 & 1,338 \\
\hline Requer um processo de orientação & 65 & 1 & 5 & 3,49 & 1,187 \\
\hline Requer um processo de acompanhamento & 65 & 1 & 5 & 3,34 & 1,338 \\
\hline Requer um processo de avaliação & 65 & 1 & 5 & 3,18 & 1,435 \\
\hline $\begin{array}{l}\text { Implica a relação entre as componentes formal e } \\
\text { não-formal do currículo }\end{array}$ & 64 & 1 & 5 & 3,14 &, 870 \\
\hline
\end{tabular}

Fonte: Dos autores.

O grau académico mais elevado correlaciona-se com a ideia de que a supervisão requer um processo de avaliação $(\mathrm{r}=.301, \mathrm{p}<0.05)$, um processo de acompanhamento $(\mathrm{r}=.364, \mathrm{p}<0.01)$ e a observação da prática letiva em sala de aula $(\mathrm{r}=.312, \mathrm{p}<0.05)$. Também a formação especializada em ADD ou supervisão pedagógica se correlaciona com a valorização da dimensão de acompanhamento $(\mathrm{r}=.250, \mathrm{p}<0.05)$.

Os resultados do estudo de Gaspar e colaboradores (2019), confirmam em parte estes resultados, na medida em que verificaram maior tendência entre os respondentes mais velhos, com mais experiência e com habilitações mais elevadas para considerar que a supervisão requer a observação da prática letiva em sala de aula (p. 113).

Pelo contrário, os docentes com maior experiência discordam mais da necessidade de a supervisão implicar acompanhamento $(\mathrm{r}=-.268, \mathrm{p}<0.05)$. Os docentes mais velhos $(\mathrm{r}=-.258$, $\mathrm{p}<0.05)$ e mais experientes $(\mathrm{r}=-.285, \mathrm{p}<0.05)$, discordam mais da necessidade de a supervisão relacionar as componentes formal e não-formal do currículo, ao contrário do que tinha sido encontrado por Gaspar e colaboradores (2019). Os docentes mais experientes estão também em maior desacordo com a ideia de que a supervisão requer um processo de avaliação $(r=-.275$, $\mathrm{p}<0.05)$.

Diferentemente, o estudo de Gaspar e colaboradores (2019) tinha identificado uma correlação entre a idade e a relação entre supervisão e liderança.

Por fim, em relação ao contexto da formação em que decorre a supervisão, os respondentes associam a supervisão à formação inicial de professores (média 3,49, DP=1,21), em coerência com aquela que é a sua própria experiência de supervisão. Situam-se na zona de indefinição avaliativa em relação à associação entre supervisão e formação contínua de professores.

Tabela 5 - Síntese de valores obtidos a partir das opiniões dos inquiridos face ao conceito de supervisão, quanto à sua relação com a formação

\begin{tabular}{l|c|c|c|c|c|c}
\hline \multicolumn{7}{c}{ Conceito de supervisão: Relação com a formação } \\
\hline $\begin{array}{l}\text { É prática no âmbito da formação inicial de } \\
\text { professores }\end{array}$ & 65 & 1 & 5 & 3,49 & 1,214 \\
\hline $\begin{array}{l}\text { É prática no âmbito da formação contínua de } \\
\text { professores }\end{array}$ & 65 & 1 & 5 & 3,05 & 1,205 \\
\hline
\end{tabular}

Fonte: Dos autores.

Práxis Educativa, Ponta Grossa, v. 16, e2117961, p. 1-21, 2021 Disponível em: <https:// revistas2.uepg.br/index.php/praxiseducativa> 
Os educadores inquiridos parecem, assim, manter-se apegados a uma conceção da supervisão mais tradicional quanto à sua relação com a formação de professores: "O conceito de supervisão, no campo pedagógico, limitou-se, tradicionalmente, à formação inicial de professores" (ALARCÃO; TAVARES, 2003, p. 16) e vários estudos corroboram que as perspetivas dos educadores sobre a supervisão pedagógica se encontram efetivamente associadas à formação inicial de professores (SANTOS; BRANDÃO, 2008; SALVADO, 2016; COSTA, 2014; FERREIRA, 2013).

\section{Conclusões:}

Os resultados desta investigação apontam para conceções e práticas de supervisão pedagógica um pouco antagónicas, pois se por um lado a generalidade dos participantes apresenta uma conceção de supervisão orientada para a melhoria das práticas docentes numa lógica formativa e de desenvolvimento profissional docente (ALARCÃO; ROLDÃO, 2010; ALARCÃO; TAVARES, 2010), a verdade é que quando questionados sobre as suas experiências prévias de supervisão, a maioria refere que a mesma teve pouco ou nenhum impacto nas suas práticas docentes, o que nos leva a questionar sobre a(s) forma(s) como a supervisão pedagógica é implementada no contexto escolar em que estão inseridos os participantes, uma vez que, tal como nos referem Abelha e Machado, a supervisão pedagógica, como estratégia de regulação, tem-se revelado, quer do ponto de vista da investigação, quer do ponto de vista das práticas, com uma elevada potencialidade para mudar as formas de trabalhar entre os professores (2018, p. 104).

Acresce que uma parte significativa dos participantes, recorda ou valoriza na sua experiência prévia ter exercido apenas o papel de supervisionado, e associa a essa supervisão pedagógica sobretudo a dois contextos específicos: o da formação inicial de professores (em contexto de estágio pedagógico) e o da avaliação do desempenho docente. De recordar que a supervisão pedagógica entrou, em Portugal, pela via da formação inicial de professores, e novamente através da ADD, o que poderá, eventualmente, contribuir para a compreensão de algumas das resistências dos educadores que participaram neste estudo.

As experiências prévias de supervisão mais assinaladas pelos educadores participantes no estudo foram a observação da prática letiva na sala de aula, a reflexão sobre as práticas desenvolvidas e a aplicação de grelhas de planificação/avaliação, formas de supervisão que se encontram plasmadas no último decreto que rege a avaliação do desempenho docente, Decreto-Regulamentar n. ${ }^{\circ}$ 26/2012 de 26 de fevereiro, que valoriza essencialmente a observação da prática letiva e o preenchimento de grelhas de avaliação como formas de supervisão.

A identificação que os participantes fazem à figura de supervisor pedagógico é consentânea com as experiências prévias de supervisão que referem ter vivenciado, destacando como principais figuras o Avaliador do Desempenho Docente, o Coordenador de Educadores de Infância, o Supervisor de Estágio (Professor Universitário) e o Orientador de Estágio (Educador da Escola), tendo sido residual a referência a processos de supervisão colaborativa, entre colegas, deixando denotar um forte pendor avaliativo e vertical no que se refere ao processo de supervisão pedagógica. Verifica-se, assim, a persistência da pesada herança deixada pela supervisão avaliativa, classificativa e que interfere não só com a profissionalidade, mas com o professor como pessoa (ALARCÃO; CANHA, 2013).

Pelo contrário, quando questionados sobre quais as funções que os educadores mais valorizam no papel do supervisor, as respostas vão no sentido de uma supervisão reflexiva e orientada para a melhoria das práticas docentes, tendo sido a promoção da reflexão a função mais valorizada. O papel do supervisor é assim perspetivado como mais abrangente, não se limitando à

Práxis Educativa, Ponta Grossa, v. 16, e2117961, p. 1-21, 2021 
função de fiscalização do trabalho docente, mas sim como desencadeador de processos de reflexão e melhoria, profissional e organizacional, isto é, que procura incutir nos educadores a capacidade de descobrir outras opções, outros caminhos de ensino e aprendizagem de acordo com os contextos educativos onde vivem sempre numa rota de reflexão e auto reflexão conforme os desafios que as escolas apresentam (ALARCÃO, 2020; ALARCÃO; TAVARES, 2010; GASPAR; SEABRA; NEVES, 2012; STONES, 1984). As funções de orientar/apoiar e a de analisar práticas foram igualmente assinaladas como funções fundamentais no papel de supervisor, o que é harmónico com a visão de Glickman (1895) trazida pelas vozes de Alarcão e Tavares (2010) que destacam dez categorias de papéis que o supervisor deve desempenhar, no qual se inclui o de orientar e o de ajudar a encontrar soluções para os problemas da prática.

Esta investigação, evidencia uma clara discrepância entre a supervisão pedagógica que os educadores consideram ter sido alvos, e aquela que consideram como prioritária, tornando-se, assim, inadiável desenvolver mecanismos de supervisão pedagógica que enalteçam a sua componente formativa e formadora e constituam uma base comum de reflexão com repercussões na melhoria da Escola e dos seus Agentes como um todo. Por outro lado, poderá indicar uma abertura e disponibilidade para abrir a sala de aula a experiências de supervisão colaborativa, horizontal e orientada para o desenvolvimento e a melhoria, o que sinaliza que essa viragem poderá ser bem recebida e frutuosa.

\section{Referências}

ABELHA, M.; MACHADO, E. A. Supervisão, colaboração e formação: relato de uma experiência com docentes de um agrupamento TEIP. Revista de Estudos Curriculares, Braga, v. 9, n. 1, p. 145-156, 2018.

AERA. Code of Ethics. Educational Researcher, v. 40, n. 3, p. 145-156, abr., 2011.

ALARCÃO, I. Escola reflexiva e supervisão: uma escola em desenvolvimento e aprendizagem. 1. ed. Porto: Porto Editora, 2000.

ALARCÃO, I. A supervisão no campo educativo. 1. ed. Aveiro: Universidade de Aveiro, 2020.

ALARCÃO, I.; CANHA, B. Supervisão e colaboração: Uma relação para o desenvolvimento. 1. ed. Porto: Porto Editora, 2013.

ALARCÃO, I.; ROLDÃO, M. C. Supervisão: um contexto de desenvolvimento profissional dos professores. 1. ed. Mangualde: Pedago, 2010.

ALARCÃO, I.; TAVARES, J. Supervisão da prática pedagógica: uma perspectiva de desenvolvimento e aprendizagem. 2. ed. Coimbra: Almedina, 2003.

ALARCÃO, I.; TAVARES, J. A supervisão da prática pedagógica: um contexto de desenvolvimento profissional dos professores. 3. ed. Coimbra: Almedina, 2010.

AMARAL, M. Supervisão pedagógica, avaliação e eficácia das escolas. 2019. Tese (Doutorado em Educação) - Universidade de Coimbra, Coimbra, 2019.

BAPTISTA, C. Supervisão e colaboração pedagógica: perspetivas de formação profissional docente em comunidade. 2019. Dissertação (Mestrado em Ciências da Educação) - Universidade Lusófona, Porto, 2019.

Práxis Educativa, Ponta Grossa, v. 16, e2117961, p. 1-21, 2021 Disponível em: <https://revistas2.uepg.br/index.php/praxiseducativa> 
BAPTISTA, I. Ética, deontologia e avaliação do desempenho docente. 1. ed. Lisboa: Ministério da Educação - Conselho científico para a avaliação de professores, 2011.

CORREIA, I.; MATOS, M. M.; FIGUEIRA, S.C. Supervisão pedagógica no contexto da formação inicial de educadores de infância: modelo de formação em alternância. In: SENHORAS, E. (org.). Políticas públicas na educação e a construção do pacto social e da sociabilidade humana 3. 1. ed. Ponta Grossa: Atena, 2021. p. 88-100.

COSTA, M. A supervisão na educação de infância: Estudos de caso na rede particular e cooperativa. 2014. Dissertação (Mestrado em Supervisão e Orientação Pedagógica) - Escola Superior de Educação de Santarém, Santarém, 2014.

CRESWELL, J. W. Projeto de pesquisa: métodos qualitativo, quantitativo e misto. Tradução de Luciana Oliveira da Rocha. 2. ed. Porto Alegre: Artmed, 2007.

FARDILHA, V. A supervisão e a qualidade da educação de infância. 2020. Dissertação (Mestrado em Ciências da Educação) - Faculdade de Ciências Humanas, Universidade Católica Portuguesa, Porto, 2020.

FERREIRA, A. A supervisão pedagógica exercida pelas estruturas de gestão intermédia e a sua influência nas práticas colaborativas docentes: Um estudo de caso. 2013. Dissertação (Mestrado em Ciências da Educação) - Escola Superior de Educação do Instituto Politécnico de Leiria, Leiria, 2013.

GASPAR, M. I.; SEABRA, F.; NEVES, C. A supervisão pedagógica: Significados e operacionalização. Revista Portuguesa de Investigação Educacional, Porto, v. 12, p. 29-57, 2012.

GASPAR, M. I. et al. Supervisão: Modelos e processos. 1. ed. Vila Nova de Gaia: Fundação Manuel Leão, 2019.

IGEC. Terceiro ciclo de avaliação externa das escolas: quadro de referência, 2018.

MAIO, N.; SILVA, H.; LOUREIRO, A. A supervisão: funções e competências do supervisor. Eduser - Revista de Educação, Bragança, v. 2, n. 1, dez. 2016.

MARCELO, C. Desenvolvimento profissional docente: passado e futuro. Sísifo - Revista de Ciências da Educação, Feira de Santana, n. 8, p. 7-22, jan./abr., 2009.

MARCOS, A.; MACHADO, E. A.; ABELHA, M. Effect(s) of teacher evaluation on collaborative practices: induction or inhibition? Procedia - Social and Behavioral Sciences, v. 174, p. 36743680, fev., 2015. DOI: https://doi.org/10.1016/i.sbspro.2015.01.1090

MCMAHON, T.; BARRETT, T.; O'NEIL, G. Using observation of teaching to improve quality: finding your way through the muddle of competing conceptions, confusion of practice and mutually exclusive intentions. Teaching in higher education, v. 12, n. 4, p. 499-511, 2007. DOI: https://doi.org/10.1080/13562510701415607

MEYER, P.; VOSGERAU, D. S. R.; BORGES, C. Colaboração entre pares em programas de desenvolvimento profissional docente. Práxis Educativa, Ponta Grossa, v. 13, n. 2, p. 312-329, 2018. DOI: https://doi.org/10.5212/praxeduc.v.13i2.0004 
MESQUITA-ALVES, F.; COSTA, J. A.; COSTA, N. Supervisão entre pares em contexto de avaliação de desempenho docente: estudo de caso sobre o segundo ciclo de avaliação (2009-2011). In. MACHADO, E. A.; COSTA, N.; ALVES, P. (org.). Avaliação do desempenho docente: compreender a complexidade, sustentar a decisão. Santo Tirso: DeFacto Editores, 2013. p. 29-43.

MIRANDA, H. Centros escolares e supervisão colaborativa: perspetivas quanto ao contributo para o desenvolvimento profissional e a melhoria das práticas pedagógicas. 2021. Dissertação (Mestrado em Supervisão Pedagógica) - Departamento de Educação e Ensino a Distância, Universidade Aberta, Lisboa, 2021.

MIRANDA, H.; SEABRA, F. Centros escolares e supervisão colaborativa: Perspetivas quanto ao contributo para o desenvolvimento profissional e a melhoria das práticas pedagógicas- um estudo em curso. Dialogia, São Paulo, v. 33, n. 1, p. 143-159, out./dez., 2019. DOI: https://doi.org/10.5585/dialogia.n33.15411

MOREIRA, M. A. A supervisão pedagógica como prática de transformação: O lugar das narrativas profissionais. Revista Eletrônica de Educação, São Carlos, v. 9, n. 3, p. 48-63, 2015. DOI: https://doi.org/10.14244/198271991380

MOREIRA, O. A supervisão pedagógica na educação pré-escolar e o seu papel nas práticas pedagógicas dos educadores de infância de carreira. 2021. Dissertação (Mestrado em Supervisão Pedagógica) - Departamento de Educação e Ensino a Distância, Universidade Aberta, Lisboa, 2021.

MOURAZ, A.; PÊGO, J. P. De Par em Par: multidisciplinar e interinstitucional. In. VIEIRA, F.; et al. (org.). Inovação pedagógica no ensino superior: ideias e práticas. Santo Tirso: De Facto Editores, 2016. p. 133-143.

NEVES, I. Supervisão e formação de profissionais de educação reflexivos: estudo de caso num estágio de um curso de formação inicial de educadores de infância. 2017. Tese (Doutorado em Educação) - Faculdade de Ciências Sociais, Educação e Tecnologias, Universidade Lusófona de Humanidades e Tecnologias, Lisboa, 2017.

OLIVEIRA, I.; MIRANDA, B.; BARREIRA, C. A construção de comunidades virtuais de aprendizagem na formação de supervisores e líderes pedagógicos. RE@D - Revista de Educação a Distância e Elearning, Lisboa, v. 3, n. 1, p. 19-36, 2020.

PARAMOS, P. Supervisão, acompanhamento e avaliação de práticas educativas e colaborativas de educadores de um jardim-de-infância - uma investigação-ação. Dissertação (Mestrado em Educação e Supervisão Pedagógica) - Universidade de Évora, Évora, 2010.

PEDRAS, S.; SEABRA, F. Supervisão e colaboração: contributos para uma relação. Revista Transmutare, Curitiba, v. 1, n. 2, p. 293-312, 2016. DOI: https://doi.org/10.3895/rtr.v1n2.4379

PEREIRA, P. As instituições de ensino superior como escolas reflexivas: Colaboração e desenvolvimento em supervisão na formação inicial de professores e educadores de infância. 2017. Dissertação (Mestrado em Estudos Profissionais Especializados em Educação) - Escola Superior de Educação, Instituto Politécnico do Porto, Porto, 2017.

ROLDÃO, M. C. Supervisão, conhecimento e melhoria: uma triangulação transformativa nas escolas? Revista Portuguesa de Investigação Educacional, Porto, v. 12, p. 7-28, 2012.

Práxis Educativa, Ponta Grossa, v. 16, e2117961, p. 1-21, 2021 Disponível em: <https://revistas2.uepg.br/index.php/praxiseducativa $>$ 
ROSA, R. O papel atribuído à supervisão na coordenação de departamento pré-escolar. 2021. Dissertação (Mestrado em Supervisão em Educação) - Escola Superior de Educação, Instituto Politécnico de Lisboa, Lisboa, 2021.

SALVADO, C. Supervisão colaborativa: Um processo de formação interpares em Jardim de Infância. 2016. Dissertação (Mestrado em Supervisão e Avaliação Escolar) - Escola Superior de Educação de Castelo Branco, Castelo Branco, 2016.

SANCHES, A. A supervisão pedagógica enquanto processo colaborativo de formação profissional. In: MESQUITA, E.; ROLDÃO, M. do C.; MACHADO, J. (org.). Prática supervisionada e construção do conhecimento profissional. 1. Ed. Vila Nova de Gaia: Fundação Manuel Leão, 2019. p. 147-163.

SANTOS, M.; BRANDÃO, M. A supervisão pedagógica numa articulação entre a preparação do educador, a formação do aluno e a qualidade da educação das crianças: a função da escala de empenhamento do adulto na concretização deste processo. Cadernos de Estudo, Porto, n. 7, p. 79-105, 2008.

SEABRA, F.; MOURAZ, A.; HENRIQUES, S.; ABELHA, M. A supervisão pedagógica na política e na prática educativa: o olhar da Avaliação Externa de Escolas em Portugal. Education Policy Analysis Archives, Arizona, v. 29, n. 106, 2021. [Aceite para publicaşão].

SERGIOVANNI, T. J.; STARRATT, R. J. Supervision: a redefinition. 7 ed. Boston: McGrawHill, 2002.

SILVA, R.; MARTINS, F. Investigar a nossa própria prática: uma experiência de auto-supervisão. Indagatio Didactica, Aveiro, v. 12, n. 3, p. 141-158, 2020.

SOBRAL, C.; CAETANO, A. Investigação-ação na formação contínua de educadoras de infância. Revista da Rede Internacional de Investigação-Ação Colaborativa, Lisboa, n. 1, p. 40-54, 2016.

SPCE. Carta ética: Instrumento de regulação ético-deontológica. 2. ed. Porto: Sociedade Portuguesa de Ciências da Educação, 2020.

STONES, E. Supervision in teacher education. London: Methuen, 1984.

VIEIRA, F. Supervisão: uma prática reflexiva de formação de professores. Porto: Asa, 1993.

VIEIRA, F. Para uma visão transformadora da supervisão pedagógica. Revista educação e sociedade, Campinas, v. 29, n. 105, p. 197-217, 2009.

VIEIRA, F.; et al. no caleidoscópio da Supervisão: imagens da formação e da Pedagogia. Mangualde: Edições Pedago, 2010.

Recebido em 08/05/2021

Versão corrigida recebida em 18/07/2021

Aceito em 19/07/2021

Publicado online em 21/07/2021

Práxis Educativa, Ponta Grossa, v. 16, e2117961, p. 1-21, 2021

Disponível em: < https://revistas2.uepg.br/index.php/praxiseducativa $>$ 